\title{
Family Psychopathology and Magnitude of Reductions in Occipital Cortex GABA Levels in Panic Disorder
}

\author{
Andrew W Goddard*, I,6, Graeme F Mason ${ }^{1,2}$, Douglas L Rothman ${ }^{3,4}$, Kevin L Behar', Ognen AC Petroff ${ }^{5}$ \\ and John H Krystal' \\ 'Department of Psychiatry, Yale University School of Medicine, USA; ${ }^{2}$ Department of Biomedical Engineering, Yale University School of Medicine, \\ USA; ${ }^{3}$ Department of Internal Medicine, Yale University School of Medicine, USA; ${ }^{4}$ Department of Radiology, Yale University School of Medicine, \\ USA; ${ }^{5}$ Department of Neurology, Yale University School of Medicine, USA; ${ }^{6}$ Department of Psychiatry, Indiana University, USA
}

Neuropsychopharmacology (2004) 29, 639-640. doi: I 0.1038/sj.npp. 1300374

Sir

In a previous publication (Goddard et al, 2001), we reported the observation of abnormally low occipital cortex total GABA levels in panic disorder (PD) (14 patients and controls pairs), as determined by spatially localized ${ }^{1} \mathrm{H}$-MRS (Rothman et al, 1993). These data provided direct, in vivo evidence implicating brain GABA neuronal dysfunction in PD. As a follow-up to this work, we wanted to determine whether there was evidence of a relationship between the family history of psychopathology and level of cortical GABA reductions in PD. We therefore performed several post hoc, nonparametric analyses on the above data set, after subgrouping patients according to their family history of depressive or anxiety psychopathology.

The family history of probable mood or anxiety psychopathology in first- (9/14 pts) and second-degree (in $2 / 14$ pts) family members was obtained by chart review, and review of the semistructured interview material (SCID, ADIS-R) (First et al, 1995; DiNardo et al, 1994). Of the relatives with anxiety disorder, three had probable generalized anxiety disorder, two post-traumatic stress disorder, three panic disorder, and one agoraphobia. One patient had separate relatives with agoraphobia and PTSD. The comparison healthy control sample utilized for the study had no lifetime or family history (in first degree relatives) of psychiatric illness by clinical assessment. The controls had been paired with the patients, retrospectively, based on sex and age, as described previously. The spectroscopy was performed on an occipital region of interest (ROI), since researchers have developed a reliable method of quantifying

\footnotetext{
*Correspondence: Dr AW Goddard, University Hospital, UH 3124, 500 N. University Blvd, Indianapolis, IN 46202, USA, Tel: + 317274 7422, Fax: + 317274 1497, E-mail: agoddard@iupui.edu

Received 12 June 2003; revised 29 September 2003; accepted 18 November 2003

Online publication: 01 December 2003 at http://www.acnp.org/ citations/Npp | 201030326 |/default.pdf
}

cortical GABA in this ROI, which has been effective in identifying cortical GABA deficits in other neuropsychiatric disorders (eg alcoholism and major depression) (Behar et al, 1999; Sanacora et al, 1999). Abnormalities in this ROI could parallel abnormalities in other cortical regions such as temporal and frontal areas, though this remains to be determined. Post hoc, nonparametric (Wilcoxon) statistical procedures were utilized for all analyses. The $\alpha$ level for all statistical analyses was set at 0.05 , and all tests were twotailed. Mean values \pm SD are reported. Values reported (see Table 1) have been adjusted to reflect corrections due to a gradient upgrade (erratum/correction submitted to the Archives of General Psychiatry, 1/18/02).

Also, to assess whether low cortical GABA in PD was independent of a family history of depression, we performed a related analysis in the same study sample, comparing PD patients without a family history of depression and matched controls (eight pairs). This analysis was also significant with patients continuing to have marked reductions in cortical GABA compared to controls (patients mean \pm SD cortical GABA level $=1.16 \pm 0.30 \mathrm{mmol} /$ $\mathrm{kg} v s$ control $\mathrm{GABA}=1.65 \pm 0.41 \mathrm{mmol} / \mathrm{kg} ; W$ statistic $=$ $-36.00, p<0.008)$.

These exploratory analyses suggest the potential contribution of family history of anxiety and depressive psychopathology to the magnitude of occipital cortex total GABA reductions observed in panic disorder. The robust cortical GABA level reduction seen in the subgroup of patients with an anxiety disorder family history did not appear to be accounted for by other clinical differences from the subgroup of patients without an anxiety family history. For example, patient variables such as medication history (the frequency of medication-naïve patients was $62 \%(5 / 8)$ in the anxiety family history subgroup $v s 66 \%$ (4/ 6 ) in patients without an anxiety family history: Fisher's exact test $p=1.00$ ), mean panic disorder severity scale (PDSS) total scores $(p<0.6)$, mean total Hamilton anxiety scale scores $(p<0.9)$, mean total clinician-rated anxiety scale (CRAS) scores $(p<0.7)$, and PDSS mean phobia scores 
Table I Occipital Cortex GABA Levels (mean \pm SD) by Family History of Psychopathology

\begin{tabular}{|c|c|c|c|c|c|}
\hline \multirow[b]{2}{*}{ Family history status of PD patients } & \multirow{2}{*}{$\begin{array}{c}\text { PD patients } \\
\text { cortical GABA } \\
\text { levels (mmol/kg) }\end{array}$} & \multirow{2}{*}{$\begin{array}{l}\text { Matched control } \\
\text { subjects GABA } \\
\text { levels ( } \mathrm{mmol} / \mathrm{kg} \text { ) }\end{array}$} & \multicolumn{2}{|c|}{ Wilcoxon statistic } & \multirow{2}{*}{$\begin{array}{l}\text { Approximate } \\
\text { effect Size }\end{array}$} \\
\hline & & & $w$ & $P$ & \\
\hline Panic disorder $(n=3)$ & $1.09 \pm 0.37$ & $|.8| \pm 0.08$ & $\mathrm{n} / \mathrm{a}$ & $\mathrm{n} / \mathrm{a}$ & 3.1 \\
\hline Nonpanic anxiety disorder $(n=5)$ & $1.08 \pm 0.27$ & $1.45 \pm 0.23$ & $\mathrm{n} / \mathrm{a}$ & $\mathrm{n} / \mathrm{a}$ & 1.5 \\
\hline Total sample $(n=14)$ & $1.08 \pm 0.31$ & $1.66 \pm 0.32$ & -105 & $<0.0001$ & 1.9 \\
\hline
\end{tabular}

*Indicates Bonferroni-corrected $p$ values. ${ }^{\#}$ Calculated by using an SD that was an average of the patient and control subsample SDs (Cohen, 1988). **indicates that

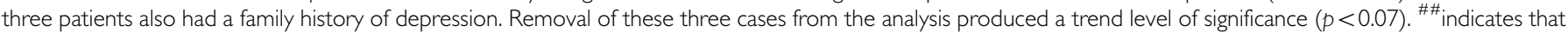
three patients also had a family history of anxiety.

$(p<0.4)$ did not differ statistically between these groups. The data, while preliminary in nature, support the contention that the magnitude of GABA neuronal dysfunction (low cortical GABA) in panic disorder could be determined by familial and possibly genetic factors. Confirmation of this result could stimulate research into panic/anxiety vulnerability genes that code for the enzymes that are required for normal GABA metabolism. However, we caution against overinterpretation of these data, since there are significant limitations inherent in this assessment, including small subgroup size, lack of formal research assessment of family psychopathology, retrospective design, and incomplete separation of both depression and anxiety family history within our study subgroups. A particular limitation with regard to sample size was the small subgroup size of patients without a family history of mood/anxiety psychopathology $(n=3$ patient/control pairs), as this meant we were unable to perform statistical comparisons between this subgroup's data and that of family history positive subgroups. These findings point to the need for prospective, comparative, follow-up studies of cortical GABA in panic disorder, utilizing larger patient groups that are mutually exclusive and carefully delineated with respect to the type of family history. This follow-up work will help determine, for example, whether PD patients with a family history of PD in first-degree relatives could be a biologically meaningful subtype of $\mathrm{PD}$, based on cortical GABA levels. It will also ascertain whether a family history of $\mathrm{PD}$ and depression independently contribute to the magnitude of cortical GABA reductions in $\mathrm{PD}$, as is suggested by our data, or whether their contribution is interrelated.

\section{REFERENCES}

Behar KL, Rothman D, Petersen KF, Hooten M, Delaney R, Petroff OAC et al (1999). Preliminary evidence of low cortical GABA levels in localized ${ }^{\star} \mathrm{H}-\mathrm{MR}$ spectra of alcohol-dependent and hepatic encephalopathy patients. Am J Psychiatry 156: 952-954.

Cohen J (1988). Statistical Power Analysis for the Behavioral Sciences, Second edn. Lawrence Erlbaum Associates: Hillsdale, NJ.

DiNardo PA, Brown TA, Barlow DH (1994). Anxiety Disorders Interview Schedule. Lifetime Version (ADIS-IV-L).

First MB, Spitzer RL, Gibbon M, Williams JBW (1995). Structured Clinical Interview for DSM-IV Axis I Disorders - Patient Edition (SCID-I/P, Version 2.0). Biometrics Research Department, New York State Psychiatric Institute: New York, NY.

Goddard AW, Mason GF, Almai A, Rothman DL, Behar KL, Petroff OAC et al (2001). Reductions in occipital cortex GABA levels in panic disorder detected with $1 \mathrm{H}$-magnetic resonance spectroscopy. Arch Gen Psychiatry 58: 556-561.

Rothman DL, Petroff OAC, Novotny EJ, Prichard JW, Shulman RG. (1993). Localized ${ }^{1} \mathrm{H}$ NMR measurements of gamma amino butyric acid in human brain in vivo. Proc Natl Acad Sci USA 90: 562-566.

Sanacora G, Mason GF, Rothman DL, Behar KL, Hyder F, Petroff OA et al (1999). Reduced cortical gamma-aminobutyric acid levels in depressed patients determined by proton magnetic resonance spectroscopy. Arch Gen Psychiatry 56(11): 1043-1047. 